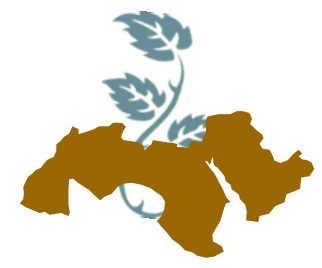

Arab Univ.

J. Agric. Sci., Ain Shams Univ., Cairo, 24(2), 465-479, 2016

\title{
ESTAMAING PRICE AND EXPENDITURE ELASTICITIES FOR MAJOR FOODS IN EGYPT DURING THE PERIOD (1980-2014) USING THE LINEAR ALMOST IDEAL DEMAND SYSTEM
}

\author{
Fayyad, B.S.
}

Higher Institute for Agricultural Cooperation, Cairo, Egypt

Keywords: Egypt. Almost Ideal Demand System (AIDS). Food Consumption. Price elasticities. Expenditure elasticities

\begin{abstract}
The objective of this research is to estimate price (direct and cross) and expenditure elasticities for major food commodities in Egypt. The food commodities are divided into six sub-models depending on the homogeneity within each group of commodities and the data availability quantities consumed and the corresponding retail prices for each individual item. Some commodities are aggregated in groups such as other beans, other vegetables, fruits(1), fruits(2) and oils. The Linear Almost Ideal Demand System (LAIDS) model is applied in estimating a system of demand equations for each group of food commodities. To avoid the invalid inference and spurious regression problems that may be created by non-stationary data series, the Fully Modified Least Squares (FMLS) estimator is utilized. The demand parameters satisfy the Engel aggregation, cournot aggregation, homogeneity and symmetry conditions.

The results indicate that expenditure elasticities of the majority of food commodities/groups are less than the unity except fot the fruits2 (1.110), indicating necessity effects. This can be also interpreted as following the increasing of consumptions of these commodities is strongly connected with increasing of all income levels. The results also show that the own price elasticities for food commodities/groups are inelastic. For fruits 2, its inelastic
\end{abstract}

own price elasticity still indicates that it tends to be very sensitive to price changes. The relative high cross price elasticities in all sub-models illustrate the strong substitute or complementary effects of the price change of one commodity one quantities consumed from other commodities in the same sub-models.

Therefore, structural implications from the estimated elasticities are important. The estimated own and cross price and expenditure elasticities must be analyzed during the economic reform for better understanding all economic changes affecting prices as well as consumption and expenditures.

\section{INTRODUCTION}

Consumer demand for food is an important component of the structure within which the agricultural sector must operate. Since the demand for food is, in general, inelastic and production or supply somewhat variable, accurate estimates of demand parameters are important as inputs for the development of national price, stabilization, trade, storage production and other policies.

Effective analysis of Egyptian agriculture and food policy requires a comprehensive view of the sector. The analysis must take into consideration the interrelationships within the agriculture sector, and in particular on the consumption side of market. For Egypt, this aspect of policy analysis is relevant especially because of the importance of linkages among food consumption, agriculture, and trade policy. The highly sensitive nature of the 
economy, especially in the reform process, requires careful and comprehensive approaches to policy. The agriculture and food sectors are important to food security and political stability and in themselves as major components of the economic system in Egypt. The modern theory of consumer behavior is the basis for estimating systems of demand equations. These systems yield estimates of own and cross price elasticities. The Linear Almost Ideal Demand System (LAIDS) model is applied in estimating a system of demand equations for food commodities. The consumer theory is valuable in indicating plausible assumptions for making estimates of demand parameters in a statistically tractable framework. In particular, the theory offers conditions under which own- and cross-price and income elasticities of demand can be estimated with an economy of parameters and with systematic behavioral interrelations.

\section{PROBLEM AND OBJECTIVES OF THE RESEARCH}

Structural implications from the estimated demand elasticities are important. The estimated own and cross price and expenditure elasticities and food policies during the economic reform must be analyzed to understand all economic changes affecting prices as well as consumption and expenditures.

Therefore, the main aim of this research is to econometrically estimate food demand elasticities. The expenditure (or income) and price elasticities of demand can be used for assessing implications of changes in income or prices on food demand that result from economic trends or changes in policies. The following are the specific objectives of the study:

- To estimate the expenditure elasticities, for the selected food commodities, and

-To estimate the own- and cross-price elasticities, for the selected food commodities.

\section{DATA}

Data necessary to estimate the parameters required for the AIDS model are retail prices and per capita food consumption. This research is mainly based on data of the consumption bulletins and Retail prices bulletins issued by Central Agency for Public Mobilization and Statistics (CAPMAS); data of the Economic Bulletins supplied by the Ministry of Internal Trade and Supply; data from the Ministry of Agriculture and Land Reclamation (MALR), the Economic Affairs Sector, the General Department of Agricultural Statistics, Egypt and data of the Food Balance Sheet issued by the FAO.

Given the available data, 6 AIDS sub-models for the 21 food commodities were estimated. Each model includes selected commodities. For example, milk \& dairy products, oils and sugar parameters are estimated in one model. The specific food groups and food commodities within the food groups used in the empirical analysis are:

- CEREALS \& STAPLES = ( Wheat, Maize , Rice and Potatoes )

- PULSES = (Bean, Peas and Other Pulses $)$

- MEATS = (Red Meat, Poultry and Fish )

- VEgETABLES = ( Onion, Tomatoes and Other Vegetables )

- FRUITS = (Citrus, Fruits 1 (Dates, Banana and Grappes) and Fruits 2 (all other fruits))

- OTHER FOODS = Eggs, Milk \& Dairy products, Oils and Sugar

The time series used to estimate the six LAIDS models is for the period 1980 to 2014. Price data are from the Statistical Yearbook and unpublished data of the Central Agency for Public Mobilization and Statistic (CAPMAS). The annual prices used for statistical analysis are simple averages of reported monthly prices and also simple averages between rural and urban areas.

Quantity data are mainly from balance sheets that adjust production for stocks, exports, imports and disappearance prepared by the Agricultural Economics Research Institute (AERI) / Ministry of Agriculture and Land Reclamation (MOALR). The data of the consumption and the prices of all commodities included in the six sub-models are included in the appendixes (1) and (2) with three averages for the periods 1980-2014, 1980-2000 and 2001-2014, respectively.

\section{THEORETICAL BASES}

\subsection{The two forms of the Almost Ideal Demand System (AIDS)}

The AIDS has been widely used in applied studies. Although the AIDS model is intrinsically nonlinear in its parameters, the linear approximation version of AIDS (LAIDS) using the Stone's share weighted price index has been widely applied to simplify the estimation process. Besides its aggregation properties, LAIDS is popular due to availability of this approximate version with linear parameters. 

the period (1980-2014)

Let a statistical model $y=f(x, \theta)+\varepsilon$, where $x$ and $y$ are two vectors of variables, $\theta$ is a vector of parameters, and $\varepsilon$ is the error term. It is said to be nonlinear in parameters if $\partial y / \partial \theta=g(\theta, x)$, which is a function of parameter $\theta$. A linear model is a special case of a nonlinear model when $\partial \mathrm{y} / \partial \theta$ $=\mathrm{h}(\mathrm{x})$, which is not a function of parameter $\theta$. The AIDS model of Deaton and Muelbauer is derived from a cost function with an appropriately defined functional form. The AIDS model is defined by:

$w_{i}=\alpha_{i}+\sum_{j} \gamma_{i j} \ln p_{j}+\gamma_{i} \ln \left(\frac{X}{P}\right)+\quad \mu \mathrm{i}$

where $w_{i}$ is the expenditure share of the $i^{\text {th }}$ good, $p_{i}$ is its price, $x$ is total expenditure of the estimated food group, $\alpha \mathrm{i}, \beta \mathrm{i}$ and $\gamma \mathrm{ij}$ are parameters to be estimated, $\mathrm{P}$ is the price index as defined in (2), $\mu \mathrm{i}$ is the error term and $\mathrm{P}$ is

$$
\ln P=\alpha_{0}+\sum_{j} \alpha_{j} \ln p_{j}+\frac{1}{2} \sum_{j} \sum_{i} \gamma_{i j} \ln p_{i} \ln p_{j}
$$

\subsection{The Price Indexes}

Most previous empirical applications have used a linear approximation for $\ln (\mathrm{P})$. The resultant AIDS is linear in parameters and the commonly used linear estimation procedures can be applied. The linear approximation is Stone's price index, defined as

$\ln P^{*}=\sum_{k} w_{k} \ln p_{k}$

To avoid many drawbacks with the stone price index in case of the LAIDS, many other price indexes have been developed. The following indexes aim also to have as much as possible similar estimates of the LAIDS as the estimates of the true AIDS.

\section{a. The Torngvist Price Index}

$\ln P_{t}^{T}=\frac{1}{2} \sum_{i=1}^{n}\left(w_{i t}+w_{i}^{0}\right) \ln \left(\frac{p_{i t}}{p_{i}^{0}}\right)$

Where $W_{l}^{0}$ and $p_{i}^{0}$ are representing the base year for the commodity share and price, respectively.

\section{b. The Paasche Price Index}

$\ln P_{t}^{S}=\sum_{i=1}^{n} w_{i t} \ln \left(\frac{p_{i t}}{p_{i}^{0}}\right)$

\section{c. The Lasperez Price Index}

$\ln P_{t}^{C}=\sum_{i=1}^{n} w_{i}^{0} \ln p_{i t}$

In both models, the true AIDS and the LAIDS, the following restrictions have to be satisfied:

\section{Adding up:}

$\sum_{i} \alpha_{i}=1, \sum_{i} \gamma_{i j}=0, \sum_{i} \beta_{i}=0$.

2. Homogeneity:

$\sum_{j} \gamma_{i j}=0$

3. Symmetry: $\quad \gamma_{i j}=\gamma_{j i}$

\subsection{Calculating of the Elasticities}

To calculate the expenditure elasticities the equation (7) is used in both models (true model and LAIDS).

$$
\mathcal{E}_{i}=1+\beta_{i} / w_{i}
$$

The calculating of the price elasticities (own and cross) can be done using equation (8) only in the true model.

$\varepsilon_{i j}=-\delta_{i j}+\gamma_{i j} / w_{i}-\beta_{i} \alpha_{j} / w_{i}-\frac{\beta_{i}}{w_{i}} \sum_{k} \gamma_{i j} \ln p_{k}$

$\varepsilon_{i j}=-\delta_{i j}+\gamma_{i j} / w_{i}$

$\varepsilon_{i j}=-\delta_{i j}+\gamma_{i j} / w_{i}-\beta_{i} \alpha_{j} / w_{i}$

$\varepsilon_{i j}=-\delta_{i j}+\gamma_{i j} / w_{i}-\beta_{i} \alpha_{j} / w_{i}-\frac{\beta_{i}}{w_{i}}\left[\sum_{k} w_{k} \ln p_{k}\left(\eta_{k j}+\delta_{i j}\right)\right]$

\subsection{Estimation Method}

The properties of series data are explored, and some data series are found to non-stationary, but cointegrated. To avoid the invalid inference and spurious regression problems that may be created by non-stationary data series, the Fully Modified 
Least Squares (FMLS) estimator is utilized. While the linear approximation form of the AIDS was used, the parameters of the last equation of each model were not estimate. They were calculated from the restrictions imposed in each of the six models. In all six LAIDS models the stone price index was used. The expenditure and price elasticities were calculated using equations (7) and (11), respectively. The total expenditure in each model is equal to the expenditures of the three or four commodities included in the model.

\section{RESULTS OF AIDS MODELS}

\subsection{Cereals \& staples}

This sub-model includes four cereals and staples commodities wheat (including wheat and wheat flour), maize, rice and potatoes. Estimated parameters for cereals are contained in Table (1). Data used in these estimates are for 1980 to 2014 . The signs of parameter estimates and their magnitude relative to their standard errors indicate that the demand specification is fairly consistent with the data.

The calculated price and expenditure elasticities for cereals given in Table (2) indicate that direct price elasticities for each commodity have a negative sign, and are all different from zero. The own price elasticities are only elastic for wheat and maize and inelastic for rice and potatoes, as expected. The estimated elasticities indicate that a 10 percent increase in the price of wheat reduces its estimated consumption by about 4.5 percent. The calculated cross price elasticities between wheat and maize have a negative sign, which indicates that consumers view the two commodities as complements rather than substitutes. Also, according to the cross price elasticities, the consumption of wheat is more affected by the change of maize price than vice versa. From the positive cross price elasticizes among wheat, maize, rice and potatoes, it is clear that the consumers are considering wheat, maize, rice and potatoes as substitutes to each other. The lowest own price elasticities are for maize followed by wheat.

The expenditure elasticities shown in Table (2) are positive, implying that all of the cereals and staples commodities are "superior." According to these four elasticities, the consumers are considering the four commodities as necessities. In general terms, these results indicate that a 10 percent increase in total expenditure is associated with an increase of about 5.6, 5.0, 6.7 and 7.9 percents in wheat and maize, rice and potatoes consumption, respectively.

\subsection{Pulses}

Data used in these estimates are for 1980 to 2014. The estimated parameters for other staples in Table (3) are encouraging, as they are for very sensitive commodities to any income changes. Most coefficients of equations in the model are statistically significant at good rejection levels.

On an economic basis, the calculated elasticities in Table (4) seem to be plausible. All own price elasticities are negative in sign and expenditure elasticities have positive signs. The own price elasticities for the three commodities are magnitudes consistent with observed consumption. The own price elasticities of beans and peas are higher compared with the own price elasticity of other beans. While the cross price elasticities between bean and peas are positive (substitute effect), all other cross price elasticities among the three commodities are negative indicating a complementary rather than a substitute effect. The price changes for beans and peas have almost the same negligible impacts on consumption on the other commodity.

While the estimated expenditure elasticity for bean, 0.561 , is lower than the estimated expenditure elasticities for peas and other beans, which indicates that the consumer considering it as a necessity.

\subsection{Meats}

This sub-model includes three commodities red meats, poultry and fish. Estimated parameters for meats are contained in Table (5). Data used in these estimates are for 1980 to 2014 . The demand specification was consistent with the data. Most coefficients of the model estimates are statistically significant.

From Table (6), the red meat own-price elasticity, -0.435 , is in the normally expected range. The poultry own-price elasticity, -0.640 , appears high than expected. However, it is important to note that according to the own price elasticities, the three commodities are considered inelastic to price changes. Consistent with the theory, all calculated cross price elasticities are negative, implying that the complementary effects. The effect of the red meat price change on poultry consumption is much less than vice versa. The cross price 

the period (1980-2014)

Table 1. Estimated parameters of the laids model for cereals \& staples between 1980 and 2014

\begin{tabular}{|c|c|c|c|c|c|c|}
\hline Commodity & Wheat & Maize & Rice & Potatoes & Expenditure & R-Square \\
\hline Wheat & $\begin{array}{c}0.192035 \\
(0.0280)^{\star \star \star}\end{array}$ & $\begin{array}{c}-0.09477 \\
(0.0116)^{\star \star \star}\end{array}$ & $\begin{array}{c}-0.06908 \\
(0.0193)^{\star \star}\end{array}$ & -0.028186 & $\begin{array}{c}-0.02061 \\
(0.00437)^{\star * *}\end{array}$ & 0.5818 \\
\hline Maize & & $\begin{array}{c}0.160059 \\
(0.16006)^{\star * *}\end{array}$ & $\begin{array}{c}-0.03657 \\
(0.00722)^{\star \star \star}\end{array}$ & -0.028716 & $\begin{array}{c}-0.00003 \\
(0.00177)^{-}\end{array}$ & 0.9463 \\
\hline Rice & & & $\begin{array}{c}0.133603 \\
(0.0214)^{\star \star \star}\end{array}$ & -0.027957 & $\begin{array}{c}0.013255 \\
(0.00451)^{*}\end{array}$ & 0.5637 \\
\hline Potatoes & & & & 0.084858 & . & \\
\hline
\end{tabular}

Table 2. Estimated price and expenditure elasticities for cereals \& staples between 1980 and 2014

\begin{tabular}{|c|c|c|c|c|c|}
\hline Commodity & Wheat & Maize & Rice & Potatoes & Expenditure \\
\hline Wheat & $\mathbf{- 0 . 4 0 9 7 9}$ & -0.17470 & -0.12571 & -0.05021 & $\mathbf{0 . 5 6 0 3 4}$ \\
Maize & -0.48741 & $-\mathbf{0 . 1 7 6 6 8}$ & -0.18808 & -0.14769 & $\mathbf{0 . 4 9 9 8 5}$ \\
Rice & -0.41260 & -0.21263 & $-\mathbf{0 . 2 8 7 5 8}$ & -0.15919 & $\mathbf{0 . 6 7 2 0 0}$ \\
Potatoes & -0.31420 & -0.29586 & -0.28767 & $\mathbf{- 0 . 1 7 4 6 7}$ & $\mathbf{0 . 7 9 2 4 0}$ \\
\hline
\end{tabular}

Source: Calculated from the results of Table (1)

Table 3. Estimated parameters of the laids model for pulses between 1980 and 2014

\begin{tabular}{|c|c|c|c|c|c|}
\hline Commodity & Bean & Peas & Others & Expenditure & R-Square \\
\hline Bean & 0.116599 & 0.026678 & -0.14328 & -0.08804 & 0.7965 \\
& $(0.0337)^{\star *}$ & $(0.0299)^{-}$ & & $(0.00940)^{\star * *}$ & \\
Peas & & 0.056505 & -0.083184 & 0.041419 & 0.5833 \\
& & $(0.0147)^{\star}$ & & $(0.00990)^{\star \star *}$ & \\
Others & & & 0.22646 & -0.046621 & \\
\hline
\end{tabular}

() Standards errors in parentheses

${ }^{* \star *}=$ significant at $1 \%{ }^{* *}=$ significant at $5 \% \quad *$ * significant at $10 \% \quad-=$ insignificant

Source: Results of the sub-model based on data data of appendixes (1) and (2).

Table 4. Estimated price and expenditure elasticities for pulses between 1980 and 2014

\begin{tabular}{|c|c|c|c|c|}
\hline Commodity & Bean & Peas & Others & Expenditure \\
\hline Bean & -0.42789 & 0.061092 & -0.19422 & 0.56102 \\
Peas & 0.00323056 & -0.62758 & -0.47900 & 0.70335 \\
Others & -0.75136 & -0.38935 & -0.261992 & 0.85271 \\
\hline
\end{tabular}

Source: Calculated from the results of Table (3)

Source: Calculated from the results of Table (3) 
Table 5. Estimated parameters of the aids model for meats between 1980 and 2014

\begin{tabular}{|c|c|c|c|c|c|}
\hline Commodity & Red Meat & Poultry & Fish & Expenditure & R-Square \\
\hline Red Meat & 0.299808 & -0.03164 & -0.26817 & -0.05185 & 0.5903 \\
& $(0.0610)^{* \star *}$ & $(0.0398)^{-}$ & & $(0.0112)$ & \\
Poultry & & 0.060445 & -0.028804 & 0.004158 & 0.6339 \\
& & $(0.0155)^{\star *}$ & & $(0.00778)^{-}$ & \\
Fish & & & 0.29697 & 0.047688 & \\
\hline
\end{tabular}

() Standards errors in parentheses

${ }^{* * *}=$ significant at $1 \%{ }^{* *}=$ significant at $5 \% \quad{ }^{*}=$ significant at $10 \% \quad$ - = insignificant

Source: Results of the sub-model based on data data of appendixes (1) and (2).

Table 6. Estimated price and expenditure elasticities for meats between 1980 and 2014

\begin{tabular}{|c|c|c|c|c|}
\hline Commodity & Red Meat & Poultry & Fish & Expenditure \\
\hline Red Meat & $\mathbf{- 0 . 4 3 4 7 9}$ & -0.039430 & -0.43700 & $\mathbf{0 . 7 1 1 2 2}$ \\
Poultry & -0.20507 & $\mathbf{- 0 . 6 4 0 3 3}$ & -0.17963 & $\mathbf{0 . 6 2 5 0 2}$ \\
Fish & -0.28477 & -0.14699 & $-\mathbf{0 . 1 4 0 9 1 1}$ & $\mathbf{0 . 9 1 0 8 7}$ \\
\hline
\end{tabular}

Source: Calculated from the results of Table (5)

elasticities show that a 10 percent increase of poultry price decreases the consumption of red meat and fish by 0.3 and 1.5 percents, respectively. The negative cross price elasticities between poultry and fish indicate that consumers view both of them as complements to each other. Also, the price change of poultry has the same impact on the consumption of fish as vice versa.

The expenditure elasticity of red meat $(0.711)$ implies that the red meat and poultry $(0.625)$ are considered as necessities. The estimated expenditure elasticity for fish (0.911) tends to be equal to the unity implying that the each expenditure (income) change will have an equal impact on its consumption.

\subsection{Vegetables}

The parameter estimates in this model are for onion, tomatoes and other vegetables. Data used in these estimates are for 1980 to 2014. Coefficients are statistically significant at high levels of rejection. The signs of parameter estimates in Table (7) relative to standard errors indicate that the specification of the demand system is consistent with the data.

The relatively low own price elasticities for vegetable commodities in Table (8) (-0.294 for onion, -0.411 for tomatoes and -0.525 for other vegetables), can be justified because that vegetables have a fixed position in the Egyptian menu. All cross price elasticities among the three commodities have negative signs indicating the complementary effects among the three of them. Also, the cross-price elasticities suggest that the price changes of onion has almost no impacts on the consumption of tomatoes and other vegetables, while the price changes of tomatoes and other vegetables have higher impacts on the consumption of onion than by its own price change. This indicates that the consumption of onions is highly linked to the consumption of tomatoes and other vegetables. This argument also explains why the consumption of other vegetables is also affected by the price change of tomatoes.

The expenditure elasticities of onion, tomatoes and other vegetables are as expected, which indicates that the consumers view these commodities as necessities.

\subsection{Fruits}

Data used in these estimates are for 1980 to 2014. Since the late 1970s fruit has increased its share in expenditure. Most signs and magnitudes of parameter estimates in Table (9), relative to their standard errors, indicate that the specification of the demand system is consistent with the data. Most coefficients of equations in the model are statistically significant at good rejection levels. 

the period (1980-2014)

Table 7. Estimated parameters of the laids model for vegetables between 1980 and 2014

\begin{tabular}{|c|c|c|c|c|c|}
\hline Commodity & Onion & Tomatoes & $\begin{array}{c}\text { Other } \\
\text { Vegetables }\end{array}$ & Expenditure & R-Square \\
\hline Onion & 0.05443 & -0.02123 & -0.033196 & -0.00315 & 0.5300 \\
& $(0.00903)^{* * *}$ & $(0.00631)^{*}$ & & $(0.00298)^{-}$ & \\
Tomatoes & & 0.240081 & -0.21885 & 0.041581 & 0.9464 \\
& & $(0.0112)^{* * *}$ & & $(0.00501)^{* * *}$ & \\
Other & & & 0.25204 & -0.038433 & \\
Vegetables & & & & & \\
\hline
\end{tabular}

() Standards errors in parentheses

${ }^{* * *}=$ significant at $1 \%{ }^{* *}=$ significant at $5 \% \quad \quad *$ = significant at $10 \% \quad-=$ insignificant

Source: Results of the sub-model based on data data of appendixes (1) and (2).

Table 8. Estimated price and expenditure elasticities for vegetables between 1980 and 2014

\begin{tabular}{|c|c|c|c|c|}
\hline Commodity & Onion & Tomatoes & Other Vegetables & Expenditure \\
\hline Onion & $-\mathbf{0 . 2 9 3 5 0}$ & -0.47498 & -0.34389 & $\mathbf{0 . 4 2 5 3 8}$ \\
Tomatoes & -0.060381 & $\mathbf{- 0 . 4 1 0 9 8}$ & -0.63786 & $\mathbf{0 . 6 0 9 2 2}$ \\
Other Vegetables & -0.054713 & -0.35386 & $\mathbf{- 0 . 5 2 4 8 3}$ & $\mathbf{0 . 7 3 3 4 0}$ \\
\hline
\end{tabular}

Source: Calculated from the results of Table (7)

Table 9. Estimated parameters of the aids model for fruits between 1980 and 2014

\begin{tabular}{|c|c|c|c|c|c|}
\hline Commodity & Citrus & Fruits(1) & Fruits(2) & Expenditure & R-Square \\
\hline Citrus & 0.089208 & -0.12314 & 0.033933 & -0.03627 & 0.6510 \\
& $(0.0249)^{\star *}$ & $(0.0289)^{\star * *}$ & & $(0.00794)^{\star * *}$ & \\
Fruits(1) & & 0.219633 & -0.096492 & -0.00573 & 0.5959 \\
& & $(0.0656)^{\star *}$ & & $(0.01091)^{-}$ & \\
Fruits(2) & & & 0.062559 & 0.041992 & \\
\hline
\end{tabular}

Source: Results of the sub-model based on data from: 1. consumption bulletins and Retail prices bulletins issued by (CAPMAS),

() Standards errors in parentheses

${ }^{* * *}=$ significant at $1 \% \quad{ }^{* *}=$ significant at $5 \% \quad *$ * significant at $10 \% \quad-=$ insignificant

Source: Results of the sub-model based on data data of appendixes (1) and (2).

The own price elasticities represented in Table (10) have negative signs. The estimated citrus, fruits (1) and fruits (2) own-price elasticities of $-330,-460,-0.879$, respectively, are plausible. The relatively high fruits (2) price elasticity is expected since this group includes all the fruits with the highest prices. With the expectation the substitute effect is between citrus and fruits (2). Also, the price change of watermelons has much less impact on the consumption of fruits (2) than vice versa, which can be also observed in the relation between citrus and fruits (2).

Expenditure elasticities of citrus, frits (1) $(0.523$ and 0.886 ) indicate that both commodities are necessities, while the high expenditure elasticities of fruits (2) indicate that this group is luxurious, due to their high prices. The consumption of fruits (2) commodities is more likely to increase with higher income than are any other commodities. 
Table 10. Estimated price and expenditure elasticities for fruits between 1980 and 2014

\begin{tabular}{|l|c|c|c|c|}
\hline \multicolumn{1}{|c|}{ Commodity } & Citrus & Fruits(1) & Fruits(2) & Expenditure \\
\hline Citrus & $\mathbf{- 0 . 3 3 0 1 4}$ & -0.32607 & -0.52607 & $\mathbf{0 . 5 2 3 7 3}$ \\
Fruits(1) & -0.29669 & $-\mathbf{0 . 4 5 9 9 9}$ & -0.22939 & $\mathbf{0 . 8 8 6 0 7}$ \\
Fruits(2) & 0.066011 & -0.29687 & $\mathbf{- 0 . 8 7 8 7 3}$ & $\mathbf{1 . 1 0 9 5 9}$ \\
\hline
\end{tabular}

Source: Calculated from the results of Table (9)

\subsection{Other commodities}

Data used in these estimates are for 1980 to 2011. Eggs, milk and other dairy products, oils and sugar are included in one sub-model. Milk and eggs are traditionally important food commodities. Not only are they protein sources, but their prices, compared to prices of other food commodities, were for a long time relative low. The share of oils and sugar trends to be very important components in the family expenditure budget. The main reason is the liberalizing of their prices.

The signs of parameter estimates and their magnitude relative to their standard errors indicate that the demand specification is fairly consistent with the data. Most estimated coefficients are statistically significant (see Table 11).
On an economic basis, the calculated elasticities in Table 12 seem to be plausible. All own price elasticities are negative in sign and are inelastic and expenditure elasticities have positive signs. The own price elasticities for the four commodities are magnitudes consistent with observed consumption. From Table (12), the eggs own-price elasticity, -0.216 , is in the normally expected range. The milk own-price elasticity, -0.671 , is higher than the other own price elasticities of this group. However, it is important to note that according to the own price elasticities, the four commodities are considered inelastic to price changes, especially the elasticities of oils and sugar $(-0.154$ and -0.165 ). Consistent with the theory, cross price elasticities between eggs and are negative, implying that the complementary effects.

According to the expenditure elasticities of the four commodities, eggs and milk are considered as necessities, especially the oils.

Table 11. Estimated parameters of the aids model for other commodities between 1980 and 2014

\begin{tabular}{|c|c|c|c|c|c|c|}
\hline Commodity & Eggs & Milk & Oils & Sugar & Expenditure & R-Square \\
\hline \multirow{2}{*}{ Eggs } & 0.050221 & -0.0453 & 0.022529 & -0.027453 & -0.00755 & 0.5786 \\
& $(0.00779)^{\star * \star}$ & $(0.0153)^{\star *}$ & $(0.00738)^{\star *}$ & & $(0.00305)^{-}$ & \\
Milk & & 0.274937 & -0.10177 & -0.12787 & 0.06023 & 0.7452 \\
& & $(0.0579)^{\star \star *}$ & $(0.0216)^{\star * *}$ & & $(0.00856)^{\star * *}$ & \\
Oils & & 0.063611 & 0.015630 & -0.01359 & 0.4329 \\
& & & $(0.0124)^{\star * *}$ & & $(0.00481)^{*}$ & \\
Sugar & & & & 0.13969 & -0.039088 & \\
\hline
\end{tabular}

() Standards errors in parentheses

*** $=$ significant at $1 \% \quad{ }^{* *}=$ significant at $5 \% \quad$ * $\quad$ significant at $10 \% \quad-=$ insignificant

Source: Results of the sub-model based on data data of appendixes (1) and (2). 

the period (1980-2014)

Table 12. Estimated price and expenditure elasticities for other commodities between 1980 and 2014

\begin{tabular}{|l|c|c|c|c|c|}
\hline \multicolumn{1}{|c|}{ Commodity } & Eggs & Milk & Oils & Sugar & Expenditure \\
\hline Eggs & $-\mathbf{0 . 2 1 5 3 9}$ & -0.36108 & 0.15572 & -0.22840 & $\mathbf{0 . 7 1 8 3 8}$ \\
\hline Milk & -0.067655 & $\mathbf{- 0 . 6 7 1 1 0}$ & -0.15056 & -0.19594 & $\mathbf{0 . 8 8 5 2 5}$ \\
\hline Oils & 0.30205 & -0.20547 & $-\mathbf{0 . 1 5 4 4 4}$ & -0.15444 & $\mathbf{0 . 4 2 2 2 5}$ \\
\hline Sugar & -0.14723 & -0.27149 & 0.10614 & $\mathbf{- 0 . 1 6 4 5 9}$ & $\mathbf{0 . 5 7 7 1 8}$ \\
\hline
\end{tabular}

Source: Calculated from the results of Table (11)

\section{Concluding observations \& recommendari-} ons

1. The main objective of this study is to provide policy and decision makers, producers and other agents of the economy with basic information about the structure of consumer demand for major food commodities. These results focus attenuation on the impact of economic changes in the economic transformation. These estimates of the own-, cross- price and expenditure elasticities are a valuable resource for anticipating impacts of the economic reform.

2. The research provides estimates for price and expenditure elasticities for 21 food commodities using LAIDS and 6 sub-models for groups of commodities. Although the results represent newly available information on the final demand for food in Egypt, they are not without limitations. Some of these limitations are particularly fertile areas of future research. Those mentioned here help to illustrate the advantages and disadvantages of the present results and to recommend areas for future work.

3. Structural implications from the estimated elasticities derived work AIDS models are important. Many economic changes affect prices as well as consumption and expenditures.

4. Several areas are specifically recommended for additional research. Using various simulations, it is easy to make some projections about changes in the structure of food consumption, after explaining the price and expenditure elasticities for each commodity. Generally, implications of the demand structure at the farm or wholesale level are much the same as those of the final demand system. This research provides a basis for future detailed analyses of the structural implications in more detail.
5. Also, the set of commodities used in this research should be extended to all food commodities. On the other hand, the elasticities for meats, vegetables, fruits, and oils could be reestimated by commodity bias and not as an aggregated group.

6. The differences between the rural and urban areas in Egypt are significant and it is difficult to estimate plausible demand systems for both together. The problem of this study was a lack of price and consumption information for both rural and urban areas. Emphasizing the demand systems to rural and urban areas will allow improved analysis of consumption patterns.

7. The effect of quality change was also not addressed. If there is quality change, then we must adjust demand estimates accordingly to reflect these different features of the food supply.

8. Finally, other researches would complement the analyses of prices and projections. Various simulations using projected prices and expenditures can test the robustness of the results and evaluate implications for estimated consumption, expenditure, and nutrition.

\section{REFERENCES}

Ahmed, S.H. 1989. Analytical Study to Estimating Family Consumption using Households Survey Data. Cairo. Institute of National Planing.

Buse, A. 1994. Evaluating the Liberalized Almost Ideal Demand System. American Journal of Agricultural Economics, 76, 781-793.

Central Agency for Public Mobilization and Statistics. Various Years. The Statistic Yearbook. 
Buse, A. 2014. Survey on Income, Expenditure and Consumption in the Arab Republic of Egypt in 2013/14. Cairo.

Deaton, A. and Muellbauer, J. 1980. An Almost Ideal Demand System. American Economics Review, 70, 312-326.

Diewert, W.E. 1987. Exact and Superlative Index Numbers. Journal of Econometrics, 4, 115145.

Eales, J.S. and Unnevehr, L. 1993. Structural Change in US Meat Demand. American Journal of Agricultural Economics, 75, 259268.

Fan, S., Wailes, E.J. and Grammer, G.L. 1995. Household Demand in Rural China: A TwoStage LES-AIDS Model. American Journal of Agricultural Economics, 77, 54-62.

Food and Agriculture Organization. Database.

Fayyad, B.S, Johnson, S.R. and EL-Khishin, M. 1995. Consumer Demand For Major Foods in Egypt. Center for Agriculture and Rural Development (CARD), Working Paper 95-WP 138.

Green, R. and Alston, J.M. 1990. Elasticities in AIDS Models. American Journal of Agricultural Economics, 72, 442-445.

Green, R. and Alston, J.M. 1991. Elasticities in AIDS Models: A Classification and Extension. American Journal of Agricultural Economics, 73, 874-875.
Hahn, W.F. 1994. Elasticities in AIDS models: Comment. American Journal of Agricultural Economics, 76, 972-977.

Hassan, Zuhair A. and Johnson, S.R. 1976. Consumer Demand for Major Foods in Canada. Agriculture Canada, Economics Branch.

Kazlauskiene, Natalia, S. Davadoss, and William H. Meyers. 1991. An Adaptive Simulation Model to Analyze Price Reform for Lithuanian Food and Agricultural Products. Report 91-BR 1. Ames: Center for Agricultural and Rural Development, lowa State University.

Ministry of Agriculture, Agricultural Economics Research Institute. 1993. National Agricultural Estimates (1987 - 1991). Cairo.

Ministry of Agriculture and Land Reclamation, Central Department of Agricultural Economics. Various Years. Agricultural Economics. Cairo.

-----, The Food Balance Sheets. Unpublished Data for the Period 1975-1992.

Moschini, G. and Vissa, A. 1992. A Linear Inverse Demand System. Journal of Agricultural and Resource Economics, 17(2), 294302.

SAS Institute Inc. 2011. SAS/ETS User's Guide. Version 9.3. Cary, NC.

Union of Egyptian Industries, Chamber of Food Industries. Unpublished Reports about the Food industries. 

the period (1980-2014) 

the period (1980-2014) 
